\title{
Start from the middle
}

The results of a year-long study of nuclear power by a distinguished panel were published last week. Colin Norman reports from Washington

IN a report likely to have a significant impact on nuclear policy in the United States, and perhaps elsewhere, a panel of distinguished scientists and economists has urged the Carter Administration to bar domestic reprocessing of spent reactor fucl, and to curtail drastically the present crash effort to develop a commercial breeder reactor. The economic justifications advanced for those two programmes are dubious at best, the panel said, and to proceed apace with either of them would seriously hamper attempts to curb the proliferation of nuclear weapons.

With the Carter Administration now in the throes of putting together a comprchensive energy policy, to be unveiled on 20 April, the report* couldn't have come at a more opportune moment. In fact, the panel's conclusions are in harmony with some of President Carter's campaign statements, and it is generally expected that the recommendations will be reflected strongly in Carter's energy policy. In any case, the report is said to have gone down well in the White House, and Carter even took time last week to meet with all 21 panel members to discuss their recommendations.

The product of a year-long study sponsored by the Ford Foundation, the report is an attempt to cxamine and stitch together the economic, political and social arguments which have been raging over nuclear power in the.past few years. The effort was initiated, according to the Ford Foundation's President, McGeorge Bundy, because of "a widespread feeling that this debate was suffering from a shortage of disinterested analysis", and the foundation therefore chose as members of the panel prestigious individuals who were not lined up on either side of the debate. Like the report of the Royal Commission on Environmental Pollution in Britain, the panel's conclusions have therefore gained some authority from the fact that the panel started from a middle-of-the-road position.

The panelists were mostly liberal academics many of whom have been

*Nuclear Power Issues and Choices (Ballinger Publishing Co., Cambridge, Mass $\$ 6.95$.) active in arms control issues, and they include two top officials in the Carter Administration-the - Secretary of Defense, Harold Brown, and Joseph Nye, deputy Under-Secretary of State (Brown was President of Caltech when he served on the panel and Nye was professor of government at Harvard). Other members included John Sawhill, former Administrator of the Federal Energy Agency, Wolfgang Panofsky, director of the Stanford Linear Accelerator Center, Kenneth Arrow, a Nobel prizewinner and professor of economics at Harvard, and Richard Garwin of IBM. The chairman of the panel was Spurgeon M. Keeny, a senior official of the MITRE Corporation, a think-tank which coordinated the effort.

With such an impressive list of authors, it's not surprising that the study has attracted considerable attention. It should be noted, however, that contrary to some interpretations, it is not an anti-nuclear document. Far from it. Though the panel challenges many of the chief arguments put forward by the nuclear industry, and opposes some programmes which the industry believes are crucial for its long-term prospects, the report neverthelcss acknowledges that uranium is likely to be an important source of energy for several decades and it suggests that in some respects nuclear power may hold a slight edge over alternative energy sources.

The panel takes issue with conventional nuclear wisdom on two points fundamental to the nuclear debate, however. It argues that, in the United States at least, although nuclear power seems to hold a slight economic advantage over coal, "the choice is so close and the uncertainties sufficiently large that the balance could easily shift to increase or eliminate" that advantage. Similarly, adverse health and social effects associated with nuclear power are likely to be less than those associated with coal, but "the range of uncertainty in social costs is so great that the balance between coal and nuclear power could be tipped in either direction".

That is a far cry from the industry's contention that the atom would supply significantly cheaper and cleaner energy than alternative sources, but it leads the panel to suggest that the United States should maintain a mix between coal and nuclear power. The recommendation is really an acknowledgment of what is likely to happen anyway.
The panel is, however, much less equivocal in its conclusions concerning plutonium. Citing nuclear proliferation as "the most serious danger associated with nuclear power", the panel urges the Carter Administration to renounce domestic reprocessing of spent reactor fuel and recycling of plutonium. "If a decision to postpone this technology indefinitely is articulated and carried out effectively", the panel argues, "it can have a major influence on the assessment of costs and benefits of reprocessing and recycle by other countries that are, or soon will be, facing similar decisions. Conservsely, a US decision to go ahead with reprocessing... would accelerate worldwide interest in the plutonium fuel cycle and undercut cfforts to limit nuclear weapons proliferation".

In any case, the panel argues that reprocessing is difficult to justify even on economic grounds. The nuclear industry has long argued that reprocessing and plutonium recycle will be needed to stretch out dwindling supplies of uranium and to pave the way for plutonium-producing breeder reactors, but the panel takes issue with the industry's chief assumptions. "Our review convinces us that current official estimates of uranium reserves and resources substantially underestimate the amounts of uranium that will be available at competitive costs", it notes, and suggests that "there will be enough uranium at costs of $\$ 40$ (1976 dollars) per pound to fuel light water reactors through this century and, at costs of $\$ 40$ to $\$ 70$ per round, well into the next century". Moreover, the panel points out that the estimated costs of reprocessing have escalated rapidly, with the result that "any net economic benefit during this century is questionable".

The panel therefore urges Carter to short-circuit a major review by the Nuclear Regulatory Commission of whether reprocessing should be permitted by announcing that the United States will defer use of the technology indefinitely. In fact, Carter promised during his election campaign that he would "seek to withold authority for commercial reprocessing until the need for, the economics and safety of this technology is clearly demonstrated", and the panel is therefore essentially urging him to keep his campaign pledge.

As for the breeder reactor programme, the panel again takes issue with the industry's economic arguments, suggesting that "the early economic potential of the breeder has been significantly overstated". The 
report also notes that a breeder programme would involve full-scale commitment to the plutonium cycle with its attendant proliferation problems. In spite of those drawbacks, however, the panel doesn't recommend complete abandonment of the programme, but suggests instead that the effort should be sharply reduced in priority and be pursued only as "insurance" against the possibility of very high future energy costs or the failure of efforts to develop alternative energy sources.

The effort to develop a commercial breeder reactor has long enjoyed pride of place as the federal government's most expensive and most controversial energy research and development programme. The expected cost of the programme has soared from $\$ 2,000$ million to $\$ 12,000$ million in the past few years, and the projected date for introduction of commercial breeder reactors has slipped from the late 1980 s to the mid 1990s. A small test reactor, the Fast Flux Test Facility, is now nearing completion in Washington State and it is expected to start operations in 1980 . The plan is to follow that with a $380 \mathrm{MW}$ demonstration reactor, construction of which was expected to begin on the Clinch River in Tennessee this year, with operation scheduled for 1983. The next step would be a large prototype reactor, funded chiefly by electricity utilities, with construction scheduled to begin in 1981 and operation in 1988. A decision on whether to proceed from the prototype to a fullscale commercial programme would be made in 1986.

The Ford Foundation study suggests that the overlapping, crash programme leading to a decision on commercialisation as early as 1986 is unwarranted, and it recommends that the effort be completely revamped with more emphasis placed on technology development. In particular, the panel recommends that the Clinch River plant be abandoned, and it suggests that the decision on commercialisation can safely be postponed beyond the end of the century.

Again, that recommendation meshes neatly with Carter's campaign pledge to reduce the breeder programme to a "relatively low priority, possibly multinational effort". Last month, moreover, Carter recommended that nearly $\$ 200$ million be cut from the Ford Administration's budget request for the breeder programme, and he ordered the Energy Research and Development Administration to undertake an intensive study of the need for and timing of the effort. That study is now under way, for ERDA established last month a committee containing some of the breeder programme's most vocal supporters and critics, and asked it to come up with recommendations before Carter's 20 April energy statement.

The Ford Foundation panel also urges the Carter Administration to take a number of other steps to reduce pressures leading to nuclear proliferation. In particular, it suggests that "the United States must have a clear policy on its long-term role in providing enriched fuel to both domestic and foreign nuclear power programs". The government should retain ownership of uranium enrichment facilities, the panel recommends, thereby reversing the Ford Administration's goal of turning enrichment plants over to private industry. The United States should also ensure that there is ample enrichment capacity in the 1980 s and 1990 s to meet international commitments, for the panel suggests that an assured fuel supply would reduce the incentive for other countries to develop their own enrichment and recycling facilities.

Finally, the panel recommends that the government should proceed promptly with plans to test the feasibility of disposing of nuclear wastes in salt beds and other stable geologic formations. Decisions on waste disposal have been continually deferred, pending introduction of reprocessing, a fact which has led to the widespread belief that reprocessing is an essential pre-requisite for permanent disposal (a belief which is written into legislation in Germany requiring that reactor wastes be reprocessed before disposal). The panel notes, however, that "spent fuel can be disposed of directly, and probably at costs comparable to those for reprocessed wastes".

\section{SERI site selected}

THE Energy Research and Development Administration (ERDA) last week conferred a much sought after plum on the State of Colorado. It selected a site in the Denver suburbs for the long-awaited Solar Energy Research Institute (SERI), a facility which could develop into the leading solar energy research centre in the United States.

Altogether nineteen organisations in 16 different states had been vying for SERI during the past year; the winner is the Midwest Research Institute, a St Louis-based research organsiation, which teamed with Colorado to offer a proposal.

To help soften the blow for some of the unlucky contenders, ERDA also announced last week that it will establish three regional solar energy research centres in New England, the Southeast, and the upper Midwest. The regional centres are expected to be run by consortia including representatives of several state governments, though their full role in the overall solar effort has yet to be determined.
SERI was called for in the Solar Energy Research, Development and Demonstration Act, a bill passed in 1974 which directed ERDA to establish a national facility and to seek the advice of the National Academy of Sciences on its role and scope. It was generally anticipated that SERI would be a large facility along the line of ERDA's nuclear laboratories.

The Academy furthered that expectation with a report recommending that SERI should be a major operation responsible for all phases of solar energy research including photovoltaics, fuels from biomass, wind power and so on. SERI should have a large budget, amounting to about $\$ 50$ million by 1980 , the Academy suggested. With very few large scientific projects up for grabs these days, such a big-league enterprise immediately generated a lot of attention and proposals came flooding into ERDA.

Early last year, however, ERDA, under pressure from the Office of Management and Budget, opted for something rather less grandiose. It announced that SERI would start small-a budget of about $\$ 5$ million for its first year-and a decision would be made early in the 1980 s on whether it should be expanded to the sort of facility the Academy had in mind. Even that scaled-down version attracted 20 separate bids, however, and ERDA shortlisted 19 of them for further study.

In announcing the selection of the Midwest Research Institute/Colorado proposal, ERDA Acting Administrator Robert Fri said last week that SERI will start with a budget of \$4-6 million for its first year, and a staff of about 75 professionals. It will cover all aspects of solar energy, but initially its functions will be mostly concerned with assessments, analyses, information dissemination, education and consultation. Its research and development activities will build up more slowly, and ultimately it could be moved to its own 300 -acre site nearby at the foot of the Rocky Mountains.

Colin Norman 